OPEN ACCESS

Edited by:

Lei Wang,

Jeju National University, South Korea

Reviewed by:

Jing Yang,

Southwest Forestry University, China

Jinguang $\mathrm{Hu}$

University of Calgary, Canada

*Correspondence:

Xin $L$

xli@nifu.edu.cn

Shang-Tian Yang

yang.15@osu.edu

Specialty section:

This article was submitted to

Industrial Biotechnology,

a section of the journal

Frontiers in Bioengineering and

Biotechnology

Received: 12 March 2021

Accepted: 01 April 2021

Published: 29 April 2021

Citation:

Li X, Zhang $Q$, Wang W and

Yang S-T (2021) A Novel

Inulin-Mediated Ethanol Precipitation

Method for Separating Endo-Inulinase

From Inulinases

for Inulooligosaccharides Production

From Inulin.

Front. Bioeng. Biotechnol. 9:679720.

doi: 10.3389/fbioe.2021.679720

\section{A Novel Inulin-Mediated Ethanol Precipitation Method for Separating Endo-Inulinase From Inulinases for Inulooligosaccharides Production From Inulin}

\author{
Xin Li ${ }^{1,2 *}$, Qiannan Zhang ${ }^{2}$, Wei Wang ${ }^{2}$ and Shang-Tian Yang ${ }^{3 *}$ \\ 1 Jiangsu Co-innovation Center of Efficient Processing and Utilization of Forest Resources, College of Chemical Engineering, \\ Nanjing Forestry University, Nanjing, China, ${ }^{2}$ Jiangsu Province Key Laboratory of Green Biomass-Based Fuels \\ and Chemicals, Nanjing, China, ${ }^{3}$ William G. Lowrie Department of Chemical and Biomolecular Engineering, The Ohio State \\ University, Columbus, $\mathrm{OH}$, United States
}

Inulin is a kind of polysaccharide that can be obtained various biomass. Inulooligosaccharides (IOS), a kind of oligosaccharides that can be obtained from inulin by enzymatic hydrolysis using inulinases, have been regarded as the functional food ingredients. Commercially available inulinases produced by natural Aspergillus niger contained both endo- and exo-inulinase activities. For IOS production from inulin, it is desirable to use only endo-inulinase as exo-inulinase would produce mainly the monosacchairde fructose from inulin. In the present study, a simple inulin-mediated ethanol precipitation method was developed to separate endo- and exo-inulinases present in natural inulinases. IOS production from inulin using the enriched endoinulinase was then optimized in process conditions including $\mathrm{pH}$ and temperature, achieving a high yield of $\sim 94 \%$. The resultant IOS products had a degree of polymerization ranging from 2 to 7 . The study demonstrated a novel method for obtaining partially purified or enriched endo-inulinase for IOS production from inulin in an efficient process.

\section{Keywords: ethanol gradient precipitation, inulin, inulinase, inulooligosaccharides, biomass}

\section{INTRODUCTION}

Inulins are polysaccharides derived from biomass, where they function as energy storage within plant biology. The chemical structures of inulin involves a mixture of linear polymers composed of fructose residues which are linked by $\beta$-2,1-glycosidic bonds, with a glucose residue through a sucrose-type linkage at the reducing end (Chi et al., 2011). Inulin can be used directly as functional ingredients for food, meaning their inclusion into edible materials imparts a benefit to human health upon consumption, such as function as dietary fiber, relieving constipation, stimulating the growth of Bifidobacteria and Lactobacillus sp. in the colon, etc (Shoaib et al., 2016; Singh et al., 2016). It is also possible to convert inulin into valuable biologically derived chemicals, such as inulooligosaccharides (IOS), citric acid, butanediol, L-lactic acid, D-lactic acid, and more (Chi et al., 2011; Zheng et al., 2018; Singh et al., 2019). 
In the recent years, IOS in particular has gained more attention for their value in functional foods. This increased interest is attributable to IOS' bifidogenic nature and health-benefiting properties. Inulin and oligofructose are "Generally Regarded As Safe (GRAS)", and used as either supplements or macronutrient substitutes (Coussement, 1999). Taking into account IOS' cost, sustainable feedstock and abundance in natural sources, inulin is considered to be a promising substrate for production of IOS (Singh et al., 2016). Inulin can be enzymatically converted to IOS using a controlled hydrolysis process involving endoinulinase, a conversion that is known to be a single step process (Singh et al., 2016). This means of conversion can be seen as having advantages when considering it from an industrial point of view, primarily due to the reaction conditions and kinetic simplicity of conversion. However, it is most certainly important to highlight the key cost driver in scaling up this conversion process: the preparation of endo-inulinase. natural inulinase is generally composed of endo-inulinase and exo-inulinase activity, as reported in a recent study (Flores et al., 2016). Inulinasedriven hydrolysis of inulin is achieved by the mechanisms of both exo-inulinase (EC 3.2.1.80), which cleaves fructose from the nonreducing end of inulin, and endo-inulinase (EC 3.2.1.7), which breaks the internal linkage of inulin to release intermediate shortchain IOS (Mutanda et al., 2008). Consequently, fructose is the major product with a little IOS in the hydrolyzate after hydrolysis of inulin by natural inulinase.

To obtain high yields of IOS from inulin, an ideal inulinase should lack extracellular exo-inulinase activity to promote more endo-inulinase activity (Singh et al., 2016). Therefore, several approaches have been carried out in recent years to promote endo-inulinase functionality. One reported approach involved chromatographic isolation of endo-inulinase from natural inulinases produced by varying microorganisms (Park et al., 1999; Cho and Yun, 2002; Jin et al., 2005; Naidoo et al., 2015). Unfortunately, the use of column chromatography is an expensive and complex approach which places significant cost burden upon an IOS process (Golunski et al., 2011). A different approach included use of a recombinant endo-inulinase to produce IOS from inulin (He et al., 2014; Xu et al., 2016; Bao et al., 2019; Jiang et al., 2019). Importantly, Aspergillus niger and the carbohydrases it produces are recognized as GRAS by the United States Food and Drug Administration (Schuster et al., 2002). However, use of recombinant enzymes is still a subject of practical and ethical debate. This mostly eliminates the aforementioned approach from being economically viable in the short term. Therefore, it remains challenging to obtain endo-inulinase with free exo-inulinase activity without amassing a wealth of additional complications.

In the present study we underwent development of a novel (as well as simple) method to separate endo-inulinase and exoinulinase activity from natural inulinases derived from $A$. niger (recall that it is GRAS). Our method is based on the differences in how endo-inulinase and exo-inulinase bind linear inulin chains. Endo-inulinase and exo-inulinase bind inulin molecules of different lengths, and also tend to precipitate at different ethanol concentrations. These intrinsic characteristics were manipulated to isolate endo-inulinase exclusively for production of IOS. Furthermore, the conditions of IOS production by the enriched endo-inulinase were optimized in temperature, inulin concentration, enzyme loading and reaction time. The goal of this work was to demonstrate practical means of using inulinase to produce valuable IOS from sustainably sourced inulin.

\section{MATERIALS AND METHODS}

\section{Materials}

Natural inulinase from A. niger (I6285) was purchased from Sigma-Aldrich (St. Louis, MO, United States). The enzyme solution, once received, was diluted to a final inulinase activity of 12.5 $\mathrm{U} / \mathrm{mL}$ and stored at $5^{\circ} \mathrm{C}$ prior to further experimentation. Inulin was purchased from Beneo Orafti (Tienen, Belgium). Ethanol of analytical purity was purchased from Nanjing Chemical Reagent Co., Ltd. and was used as received without further purification.

\section{Inulin-Mediated Ethanol Gradient Precipitation}

Phase I: The initial ethanol solution (40-60\%, v/v) was cooled in a water-ice bath for $30 \mathrm{~min}$, and then $\mathrm{pH}$ adjusted to 4.6. Next, $20 \mathrm{~mL}$ of the chilled and $\mathrm{pH}$-adjusted ethanol solution was mixed with $0.8 \mathrm{~g}$ inulin (Beneo Orafti, Belgium) and the natural inulinase. This mixture was kept at $0^{\circ} \mathrm{C}$ for $2-4 \mathrm{~h}$. After time, the precipitates (named P40, P45, P50, P55, and P60, respectively) was recovered by centrifugation at 2,000-3,000 $\mathrm{g}$ and $0^{\circ} \mathrm{C}$ for $10 \mathrm{~min}$, which is according to the work of Gu et al. (2020).

Phase II: Following Phase I, the supernatant (ethanol 60\%, $\mathrm{v} / \mathrm{v}$ ) was as the initial solution of Phase II. Additional chilled ethanol (at a temperate of $-20^{\circ} \mathrm{C}$ ) was dropwise added into the supernatant to reach an ethanol concentration of $65 \%(\mathrm{v} / \mathrm{v})$. This new mixture was also then kept at $0^{\circ} \mathrm{C}$ for $2-4 \mathrm{~h}$. A newly precipitated fraction was recovered by centrifugation (same parameters as before) and dubbed $\mathrm{P} 65$. This process was repeated in a step-wise fashion to obtain precipitates P70, P75, and P80.

Each recovered precipitate was re-dissolved in sodium acetate buffer ( $\mathrm{pH} 4.6,100 \mathrm{mM}$ ) prior to determine enzyme activity or use in bioconversion. The ethanol gradient precipitation of inulin without the natural inulinase was the same process as above. All experiments were carried out in triplicate.

\section{Determination of Enzyme Activity}

Enzyme activity was measured by proxy using the concentration of reducing sugars released from inulin and sucrose. Inulin (Beneo Orafti, Belgium) was used as the substrate for determination of inulinase activity. Sucrose (Sinopharm, China) was used as substrate for determination of sucrase activity. A reaction mixture containing $50 \mu \mathrm{L}$ of diluted crude enzyme and $450 \mu \mathrm{L}$ of $5 \%(\mathrm{w} / \mathrm{v})$ substrate solution (dissolved in $0.1 \mathrm{M}$ sodium acetate buffer, $\mathrm{pH} 4.6$ ) was incubated at $60^{\circ} \mathrm{C}$ for $10 \mathrm{~min}$. A denatured enzyme in inulin or sucrose solution was also used to serve as an experimental control. The amount of reducing sugars liberated from inulin or sucrose was determined using a 3,5-dinitrosalicylic acid (DNS) assay (Xu et al., 2016), 
with fructose serving as a standard. Assay response was measured as absorbance at $520 \mathrm{~nm}$. Regarding enzyme activity derived from said assay, one unit of inulinase activity or sucrase activity was defined as the amount of enzyme required that produced $1 \mu \mathrm{mol}$ of reducing sugar per minute under the assay conditions used in this study.

\section{Inulooligosaccharides Production by Enzyme Hydrolysis of Inulin}

Inulin (Beneo Orafti, Belgium) was used as the substrate for IOS production. Enzymatic hydrolysis of inulin was carried out under different conditions, including temperature, substrate concentration, enzyme loading, and reaction time. Samples of the hydrolyzates $(1 \mathrm{~mL})$ were taken at different intervals and boiled at $100^{\circ} \mathrm{C}$ for $5 \mathrm{~min}$ to denature the enzymes and cease further bioconversion. Following denaturing, all samples were centrifuged at $10,000-12,000 \mathrm{~g}$ for $5 \mathrm{~min}$, and the supernatants were analyzed by high-performance anion exchange chromatography quantitatively coupled with pulsed ampere detection (HPAEC-PAD). The details of this chromatography method are described in the following section.

\section{Analytical Methods}

Quantitative analysis of IOS was carried out in accordance with the reported analytical method (Xu et al., 2016), albeit with some modifications. Measurement of resultant IOS concentrations was performed using a HPAEC-PAD with a CarboPac PA200 column (250 mm $\times 3 \mathrm{~mm}$, Dionex, Sunnyvale, CA, United States). Water, $200 \mathrm{mM} \mathrm{NaOH}$ and $500 \mathrm{mM}$ sodium acetate (NaAc) were used as the mobile phase. A gradient elution strategy was implemented as follows: $60 \%$ water, $40 \% 200 \mathrm{mM} \mathrm{NaOH}$ and $0 \rightarrow 12 \% 500 \mathrm{mM}$ $\mathrm{NaAc}$ in $0-5 \mathrm{~min} ; 48 \%$ water, $40 \% 200 \mathrm{mM} \mathrm{NaOH}$ and $12 \%$ $500 \mathrm{mM} \mathrm{NaAc}$ in 5-25 min; $48 \rightarrow 20 \%$ water, $40 \% 200 \mathrm{mM}$ $\mathrm{NaOH}$ and $12 \rightarrow 40 \% 500 \mathrm{mM} \mathrm{NaAc}$ in $25-30 \mathrm{~min} ; 20 \rightarrow 0 \%$ water, $40 \rightarrow 100 \% 200 \mathrm{mM} \mathrm{NaOH}$ and $40 \rightarrow 0 \% 500 \mathrm{mM} \mathrm{NaAc}$ in $30-33 \mathrm{~min} ; 100 \% 200 \mathrm{mM} \mathrm{NaOH}$ in $33-35 \mathrm{~min} ; 0 \rightarrow 60 \%$ water and $100 \rightarrow 40 \% 200 \mathrm{mM} \mathrm{NaOH}$ in $35-50 \mathrm{~min}$. The column temperature was $30^{\circ} \mathrm{C}$, and the flow rate was $0.4 \mathrm{~mL} / \mathrm{min}$. The method showed that IOS quantitation had a good linear relationship within the $0.1-10 \mathrm{mg} / \mathrm{L}$ concentration range. IOS yields were calculated as the ratio of total IOS $(\mathrm{g})$ to the inulin $(\mathrm{g})$. IOS are a group of oligosaccharides, which is formed by $\beta-(2-1)$ linked fructofuranosyl unit on the end of sucrose molecule, with degree of polymerization (DP) ranging from 2 to 10 (Singh et al., 2016). In the name of simplicity, we arbitrarily defined IOS with chain lengths between 2 and 10 residues. Glucose $(\mathrm{G})$, fructose (F), sucrose (GF), 1-kestose (GF2), 1-nystose (GF3), 1-F-1- $\beta$-Dfructofuranosyl nystose (GF4), 1-F-(1- $\beta$-D-fructofuranosyl) -2nystose (GF5) and 1-F-(1- $\beta$-D-fructofuranosyl) -3-nystose (GF6) were quantitatively determined by an external standard method, and others were estimated by the ratio of their peak areas to total peak areas of HPAEC.

Gel permeation chromatography (GPC) analysis of inulin was carried out at $35^{\circ} \mathrm{C}$ with an Agilent 1,260 HPLC equipped with two columns (Ultrahydrogel-120 and Ultrahydrogel-250). $50 \mathrm{mM}$ potassium dihydrogen phosphate was used as the mobile phase. Mobile phase flow rate was $0.6 \mathrm{~mL} / \mathrm{min}$. The $\mathrm{DP}$ value was calculated according to the equation as follows:

Average molecular weight $(\mathrm{g} / \mathrm{mol})=162 \times(\mathrm{DP}-1)+180$

\section{Statistical Analysis}

Statistical analysis was carried out using Origin 2016 software (OriginLab Corporation, Northampton, MA 01060, United States). The data were assessed using a one-way ANOVA with Tukey's test.

\section{RESULTS AND DISCUSSION}

\section{The Inulin-Mediated Ethanol Gradient Precipitation of Natural Inulinase From Aspergillus niger}

Aspergillus niger is known to produce inulinases with high levels of endo- and exo-inulinase activities (Singh and Gill, 2006). Exo-inulinase removes one fructose from the nonreducing end of inulin, whereas endo-inulinase randomly cleaves the $\beta$-2,1-glycosidic bonds in inulin (Qiu et al., 2018). Two different hydrolytic behaviors implied that there are different binding properties existing between inulinases and inulin. To check the idea, ethanol gradient precipitation was applied to explore inulin-binding properties of inulinases. We qualitatively precipitated inulinase by ethanol gradient precipitation both in the presence and absence of inulin at ethanol concentration ranging from $40 \%(\mathrm{v} / \mathrm{v})$ to $80 \%$ (v/v) (Supplementary Figure S1). An interesting phenomenon was found that precipitates were obtained at different ethanol concentrations in the presence of inulin while no precipitates were observed when the system had no inulin dissolved within. Comparably, precipitates, showing higher relative inulinase activity (in redissolved form) were also observed at ethanol concentrations of $50 \%(\mathrm{v} / \mathrm{v})$ and $70 \%(\mathrm{v} / \mathrm{v})$, respectively. These results demonstrate that inulinases will not precipitate if not in the presence of inulin. This suggests that some sort of association occurs between the enzymes of interest and inulin, which then allows the coordinated enzymes to be precipitated along with the substrate inulin. In addition, results in Table 1 demonstrate that longer chains of inulin are prone to precipitate at lower ethanol concentrations compared to inulin molecules of shorter length (Xu et al., 2014). Based on all of these findings, we inferred that the two precipitates might be two different inulinases, and one tend to bind the longer chain inulin molecules while the other was likely to bind the shorter chain inulin molecules. Furthermore, ethanol gradient precipitation

TABLE 1 | Estimated molecular weights of inulin precipitates.

\begin{tabular}{lcc}
\hline & $\begin{array}{c}\text { Average molecular } \\
\text { weight (g/mol) }\end{array}$ & $\begin{array}{c}\text { Degree of } \\
\text { polymerization }\end{array}$ \\
\hline Inulin as control & 3,260 & 20 \\
$50 \%(\mathrm{~V} / \mathrm{v})$ ethanol & 4,730 & 29 \\
$70 \%(\mathrm{~V} / \mathrm{v})$ ethanol & 3,730 & 22
\end{tabular}



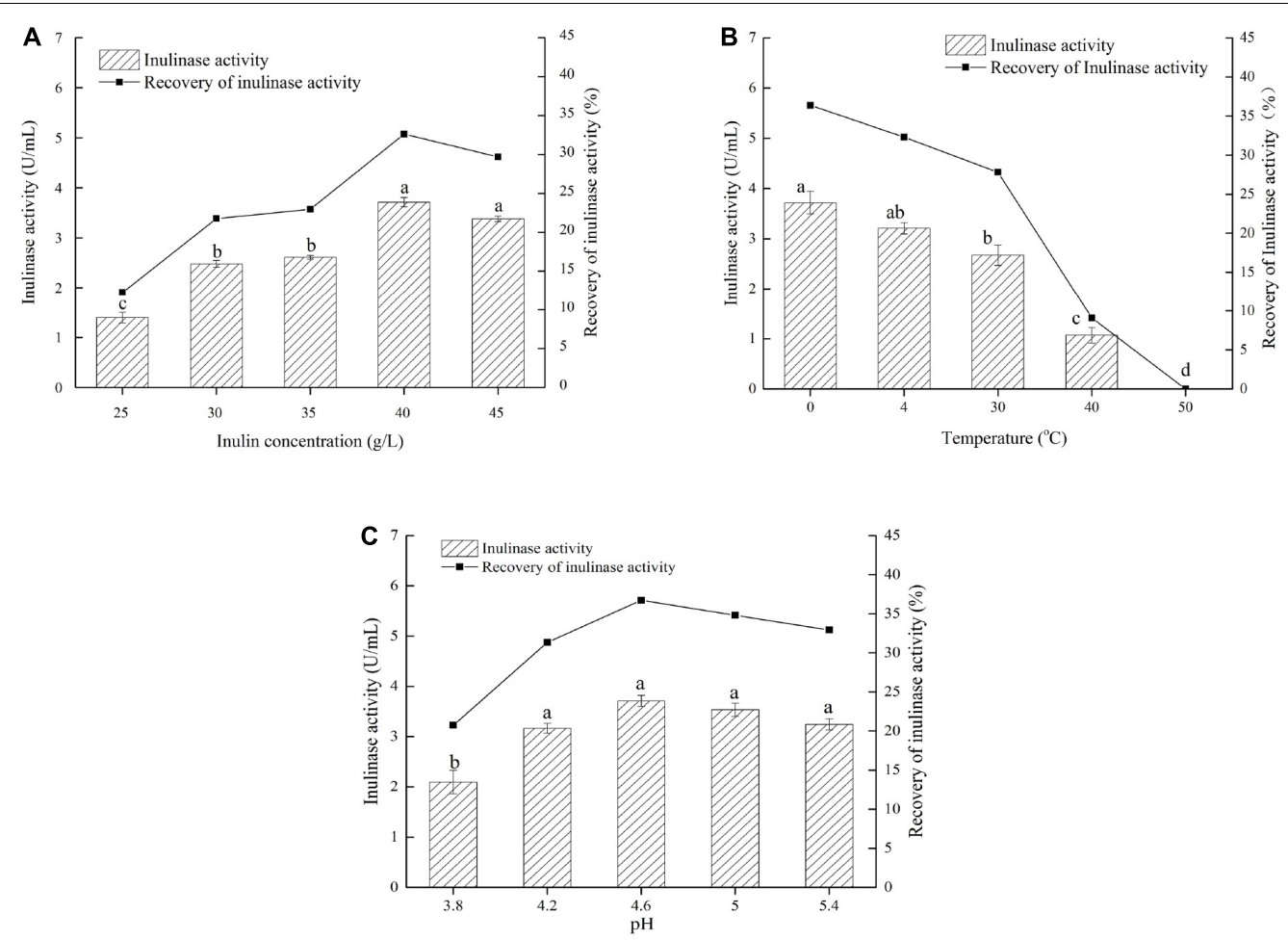

FIGURE 1 | Effects of inulin concentration, temperature and $\mathrm{pH}$ on the inulin-mediated ethanol precipitation of natural inulinase from Aspergillus niger. The conditions of the inulin-mediated ethanol precipitation were as follow: (A) $0^{\circ} \mathrm{C}, \mathrm{pH} 4.0-5.0$ and ethanol concentration of 55\% (v/v); (B) $40 \mathrm{~g} / \mathrm{L}$ inulin, $\mathrm{pH} 4.0-5.0$ and ethanol concentration of $55 \%(\mathrm{v} / \mathrm{v})$; (C) $40 \mathrm{~g} / \mathrm{L}$ inulin, $0^{\circ} \mathrm{C}$ and ethanol concentration of $55 \%(\mathrm{~V} / \mathrm{v})$. Lower case letters: Significant differences $(p<0.05)$. Statistical analysis was performed using a one-way ANOVA with Tukey's test.

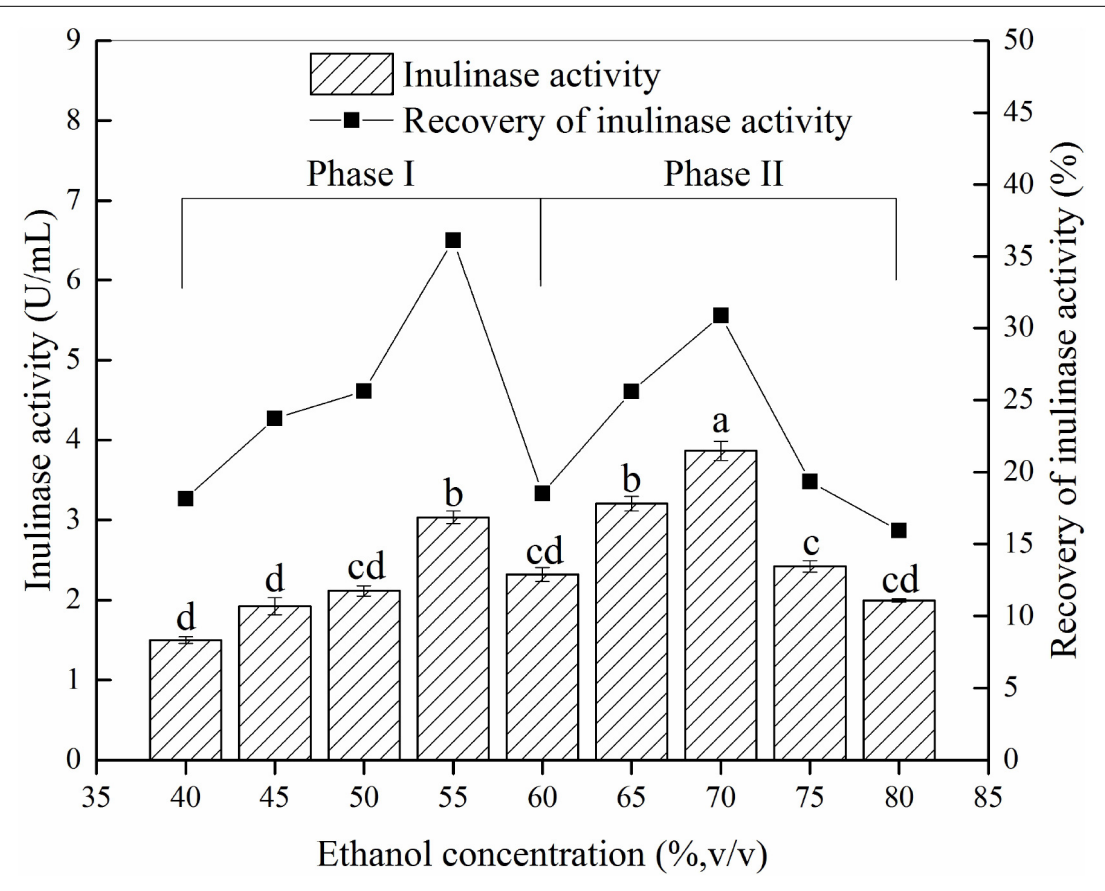

FIGURE 2 | The inulin-mediated ethanol gradient precipitation of natural inulinase from Aspergillus niger. The conditions of the inulin-ethanol precipitation were as follows: $40 \mathrm{~g} / \mathrm{L}$ inulin, $0^{\circ} \mathrm{C}$ and $\mathrm{pH} 4.6$. Lower case letters: Significant differences $(p<0.05)$. Statistical analysis was performed using a one-way ANOVA with Tukey's test. 
TABLE 2 | The different enzyme activities of precipitates from the inulin-ethanol precipitation of natural inulinase from Aspergillus niger.

\begin{tabular}{lccc}
\hline Precipitate & $\begin{array}{c}\text { Inulinase activity } \\
(\mathbf{I}, \mathbf{U} / \mathbf{m L})\end{array}$ & $\begin{array}{c}\text { Sucrase activity } \\
(\mathbf{S}, \mathbf{U} / \mathbf{m L})\end{array}$ & I/S ratio \\
\hline P55 & 3.0 & 1.6 & 1.9 \\
P70 & 3.9 & 0.1 & 39 \\
\hline
\end{tabular}

might be an effective method to separate endo-inulinase from exo-inulinase present in the natural inulinases.

Based on the findings mentioned above, we explored a simple and quick method to separate different inulinases from natural inulinase. In the present work, inulin-mediated ethanol gradient precipitation was carried out to separate different inulinases from natural inulinase. $40 \mathrm{~g} / \mathrm{L}$ inulin and $0^{\circ} \mathrm{C}$ were identified as the optimal conditions for inulinethanol precipitation (Figures 1A,B). In addition, $\mathrm{pH} 4.6$ was determined to be the optimum $\mathrm{pH}$ for the selective isolation (Figure 1C).

Different ethanol concentration demonstrated a significantly effect on precipitation and recovery of inulinase (Figure 2). The results showed that precipitates P55 and P70 [corresponding to the material precipitated at 55\% ethanol (Phase I) and 70\% ethanol (Phase II), respectively] contained greater inulinase activity (Figure 2), with both recovering about $67 \%$ initial inulinase activity. However, because different proteins tend to precipitate at different aqueous ethanol concentrations (van Oss, 1989), we thus inferred that P55 (Phase I) and P70 (Phase II) could be two different inulinases.

To explore this hypothesis, we next carried out another experiment to characterize the precipitates P55 and P70 for both inulinase activity and sucrase activity (Table 2). Generally, a simple identification of endo- and exo-inulinase activity is characterized by the ratio of inulinase (I) activity: sucrase (S) activity (Ettalibi and Baratti, 1987; Kango, 2008). Ettalibi and Baratti (1987) reported that the I/S ratio of endo-inulinase was higher than that of exo-inulinase. Wang et al. (2003) also reported that the I/S ratio of exo-inulinase was lower than 10 , while that of endo-inulinase was higher than 10. In our experiment, the drastic difference in I/S ratio between P70 (39) and P55 (1.9) confirmed the different enzymatic composition of P70 and P55, which was expected given that what precipitated at $70 \%$ ethanol remained in solution during P55 preparation. Nevertheless, the results suggested that P55 contained mostly exo-inulinase while P70 contained mostly endo-inulinase. According to SDSPAGE analysis (Figure 3), P70 and P55 consisted of several different protein bands, respectively, indicating that no single protein band could be obtained by the inulin-mediated ethanol gradient precipitation.

\section{Inulin Hydrolysis by Fractionated Inulinases}

As discussed earlier, we conjectured that P55 would exhibit strong exo-inulinase activity while P70 should demonstrate high levels of endo-inulinase activity. We tested the hydrolytic behaviors of P55 and P70 by performing enzymatic hydrolysis

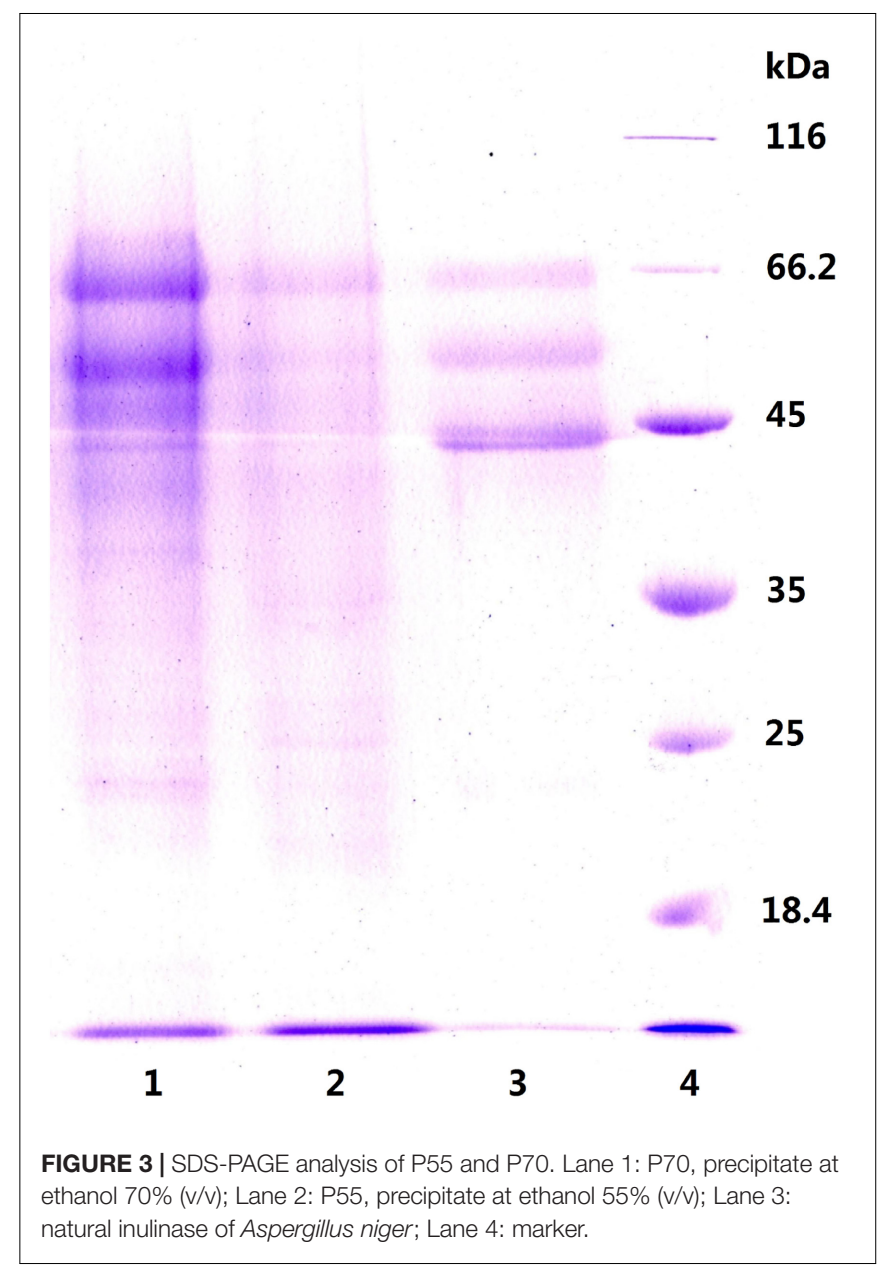

of inulin at the enzyme loading of $10 \mathrm{U} /(\mathrm{g}$ inulin) (Figure 4). At $0 \mathrm{~h}$, it can be seen that minute quantities of IOS and fructose were already present in the inulin substrates. As shown in Figure 4A, fructose concentrations significantly increased over time while IOS concentrations gradually decreased. The behavior of P70 was completely different from that of P50, where it can be seen that IOS concentrations continued to increase with hydrolysis times while fructose concentrations remained relatively constant (Figure 4B). In bioconversion using P70, the maximum IOS concentrations and yields were obtained at $15 \mathrm{~h}$ (No significant difference between 15 and $24 \mathrm{~h}$ ), and likely would have further increased given more hydrolysis time (albeit to a likely minor extent). From these observations, it can be seen that inulin was predominantly hydrolyzed into fructose by P55, whereas P70 exclusively acted upon hydrolyzing inulin to IOS. According to their respective inulin hydrolytic mechanisms, endo-inulinases act by producing IOS while exo-inulinases hydrolyze inulin and IOS to form fructose (Chi et al., 2009). Therefore, our results show that the precipitate P55 was dominated by exo-inulinase activity, and the precipitate P70 was dominated by endo-type inulinase activity. These findings further indicate that the inulin-mediated ethanol gradient precipitation method was effective for obtaining 

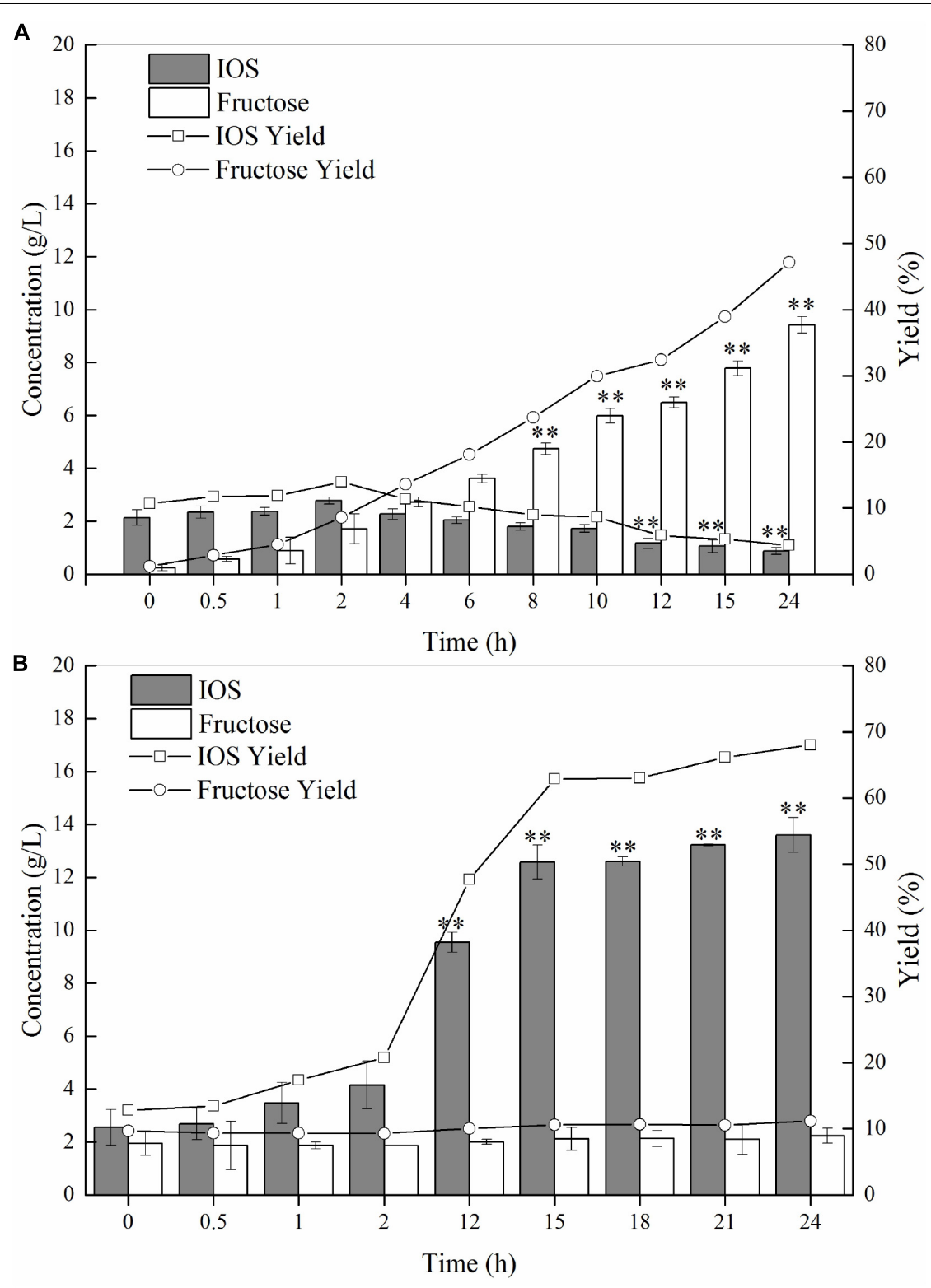

FIGURE 4 | Inulin hydrolysis by P55 (A) and P70 (B). The conditions of 24 h-enzymatic hydrolysis were as follow: $20 \mathrm{~g} / \mathrm{L}$ inulin, $10 \mathrm{U}$ inulinase activity per gram of inulin, $50^{\circ} \mathrm{C}$ and $\mathrm{pH}$ 4.6. Statistical analysis was performed using a one-way ANOVA with Tukey's test to determine a significant increase or decrease of IOS or fructose compared with those at $2 \mathrm{~h}(\mathrm{p}<0.01)$. ${ }^{* *}$ Indicates a statistical significance.

endo-inulinase activity which would be effective in producing IOS at industrial scales.

\section{Optimization of IOS Production by Fractionated Endo-Inulinase}

To further demonstrate effective IOS production using the enzyme preparation which was dominant in endo-inulinase activity (P70), enzymatic hydrolysis conditions (temperature, inulin concentration, enzyme loading, and reaction time) were investigated and optimized. As shown in Figure 5A, temperatures demonstrate notable influences on both IOS concentrations and yields, and the optimum temperature for inulin hydrolysis was $50^{\circ} \mathrm{C}$. At this temperature, a maximum IOS yield of $69.7 \%$ and maximum IOS concentration of $20.9 \mathrm{~g} / \mathrm{L}$ was achieved. Next, the effect of the inulin concentration was investigated in the range of $30-70 \mathrm{~g} / \mathrm{L}$. Figure 5B shows that an IOS yield of $68 \%$ was obtained at $40 \mathrm{~g} / \mathrm{L}$ inulin. When the inulin concentration was higher than $40 \mathrm{~g} / \mathrm{L}$, the IOS yield decreased gradually. However, the IOS yields were in the range of $60 \%$ to $70 \%$. This result suggests that the inulin concentration has a little effect on IOS yield.

Concerning optimal enzyme loading (Figure 5C), IOS yields were unsurprisingly larger (80\%) when the enzyme loading 

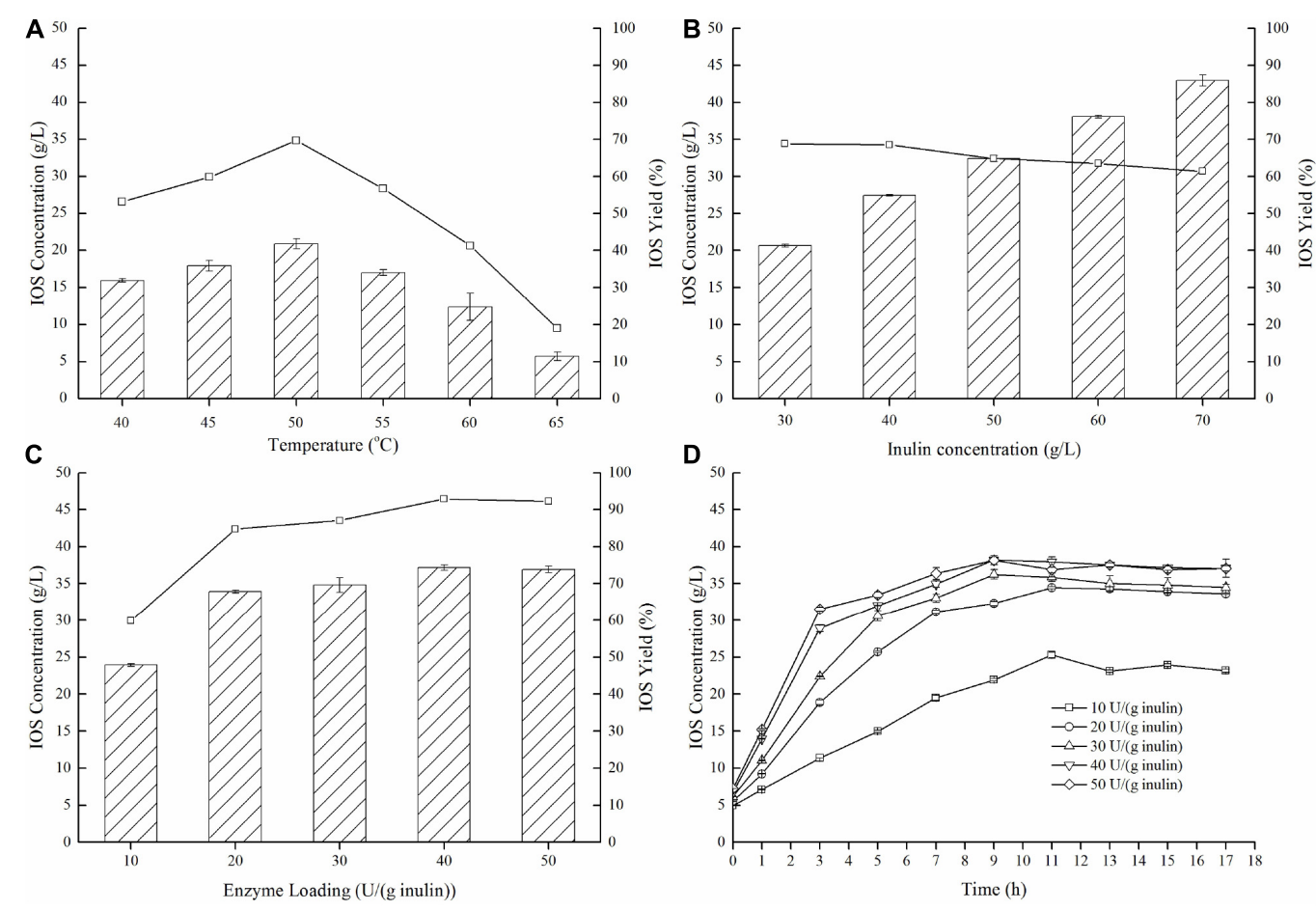

FIGURE 5 | Effects of temperature (A), inulin concentration (B), and enzyme loading (C,D) on the production of IOS from inulin by the isolated endo-inulinase. (A) Effect of temperature on IOS production. The conditions of $15 \mathrm{~h}$ enzymatic hydrolysis were as follow: $30 \mathrm{~g} / \mathrm{L}$ inulin, $10 \mathrm{U}$ endo-inulinase per gram of inulin and pH 4.6. (B) Effect of inulin concentration of IOS production. The conditions of $15 \mathrm{~h}$ enzymatic hydrolysis were as follow: $10 \mathrm{U}$ endo-inulinase per gram of inulin, $\mathrm{pH} 4.6$ and $50^{\circ} \mathrm{C}$. (C) Effect of enzyme loading on IOS production. The conditions of $15 \mathrm{~h}$ enzymatic hydrolysis were as follow: $40 \mathrm{~g} / \mathrm{L}$ inulin, $\mathrm{pH} 4.6$ and $50^{\circ} \mathrm{C}$. (D) Time course of IOS production by different enzyme loading of endo-inulinase. The hydrolytic conditions were as follow: $40 \mathrm{~g} / \mathrm{L}$ inulin, $\mathrm{pH} 4.6$ and $50^{\circ} \mathrm{C}$.

was greater than $20 \mathrm{U} /(\mathrm{g}$ inulin). It can also be seen that the yield benefits to increasing enzyme loading beyond $20 \mathrm{U} /(\mathrm{g}$ inulin) were marginal at best, eliminating any expensive need to dose high levels of enzyme in a real process. Finally, the time course of inulin hydrolysis at different enzyme loadings is shown in Figure 5D. For the enzyme loading of $10 \mathrm{U} /(\mathrm{g}$ inulin), the maximum IOS concentration $(25.3 \mathrm{~g} / \mathrm{L})$ was observed at $11 \mathrm{~h}$ with an IOS yield of $63.2 \%$. Comparably, the maximum IOS concentrations (over $32 \mathrm{~g} / \mathrm{L}$ ) were observed at $9 \mathrm{~h}$ for all of the enzyme loadings between $20 \mathrm{U} /(\mathrm{g}$ inulin) and $50 \mathrm{U} /(\mathrm{g}$ inulin). This finding indicates that increasing endoinulinase loading notably enhanced IOS concentrations and shortened required hydrolysis time at constant initial inulin concentrations. It should be pointed out that a higher IOS concentration $(38.2 \mathrm{~g} / \mathrm{L})$ was observed at $9 \mathrm{~h}$, representing the IOS yield of $95.4 \%$ at $40 \mathrm{U} /(\mathrm{g}$ inulin). Interestingly, further increasing hydrolytic time resulted in a slight decrease in IOS concentration. This result suggested that the endo-inulinase fraction did bear a slight level of exo-inulinase activity that could not be eliminated despite the fractionation protocol utilized. To minimize this occurrence, the optimal hydrolytic time was identified as $9 \mathrm{~h}$.

\section{Distribution of Hydrolytic Products}

To determine distribution of hydrolytic products produced by our endo-inulinase, a separate hydrolysis experiment using fresh enzyme and inulin was carried out with $40 \mathrm{~g} / \mathrm{L}$ inulin, enzyme loading of $40 \mathrm{U} /\left(\mathrm{g}\right.$ inulin), at $\mathrm{pH} 4.6$, and $50^{\circ} \mathrm{C}$ for a total of $9 \mathrm{~h}$. For comparison, a similar experiment was also performed using the natural inulinase. The distributions of reaction products in each hydrolyzate are shown in Figure 6. Beginning with Figure 6A, the major products produced using the endoinulinase were oligosaccharides ranging from DP 2 to DP 7, which represented more than $94 \%$ of the hydrolyzate. Within this DP range, $85 \%$ of hydrolyzate components were between DP 4 and DP 7. The overall distribution of hydrolysis products was as follows: GF3 4.7\%, inulotriose (F3) 26.4, GF4 9\%, inulotetraose (F4) 19.3, GF5 7, inulopentaose (F5) 13.1, and GF6 5.5\%. In contrast, fructose and glucose were the main products from inulin hydrolysis using natural inulinase (Figure 6B). Both of them contributed over $87 \%$ of hydrolyzate components, and little oligosaccharides were found in the hydrolyzate. This result means natural inulinase hydrolyzed inulin into monosaccharides within a 9-h enzymatic hydrolysis.

It has been reported that endo-inulinases purified from different microorganisms can produce IOS from inulin at yields ranging from 70 to $92 \%$ (Singh et al., 2016). In these cases, an endo-inulinase of Aspergillus ficuum was purified by column chromatography, and then used to hydrolyze inulin (Jin et al., 2005). In said study, the IOS products mainly consisted of DP 3 and DP 4 oligosaccharides, and the yield of $86 \%$, major products of DP 5 and DP 6, was obtained by the endo-inulinase from 

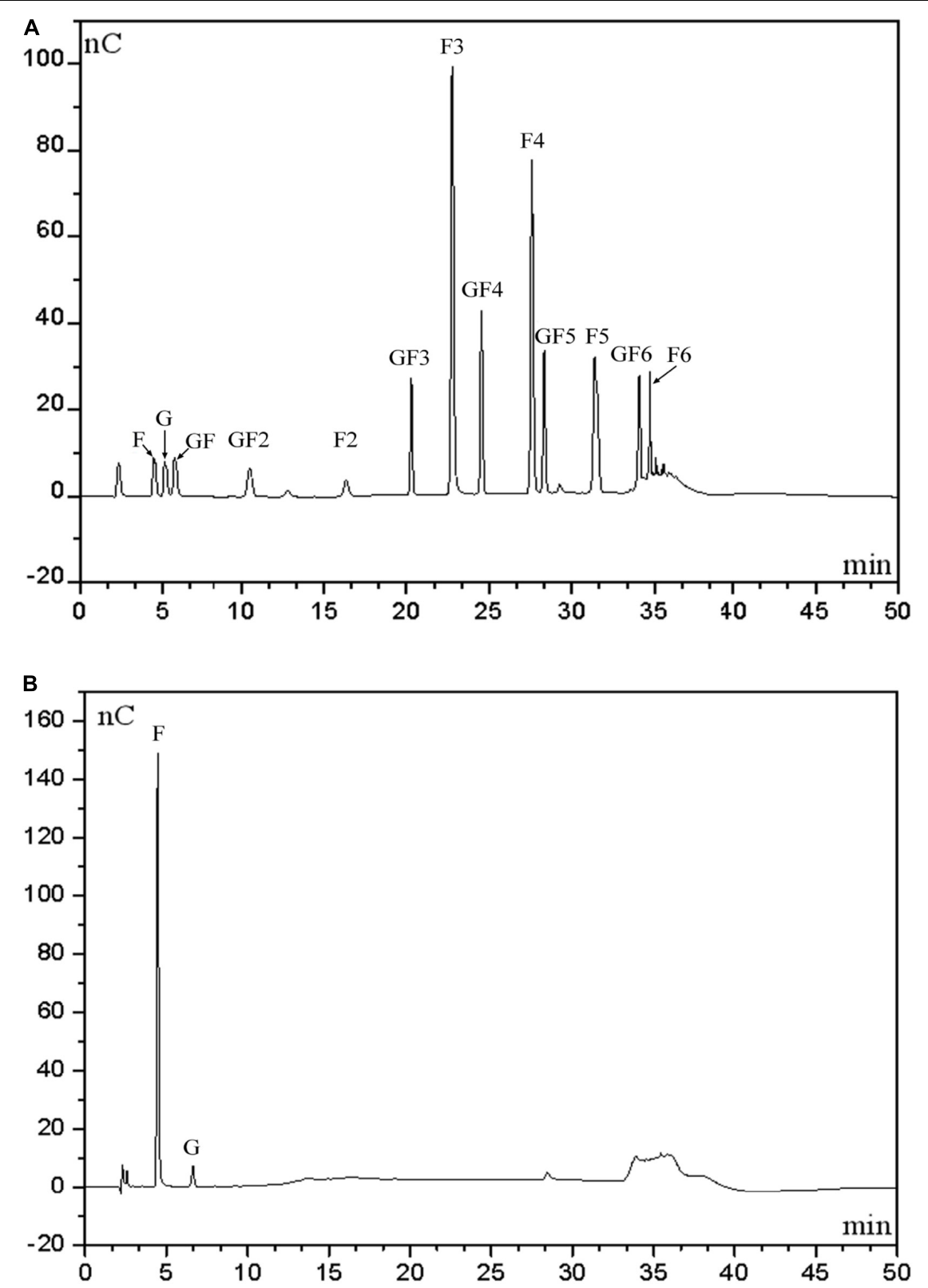

FIGURE 6 | High-performance anion exchange chromatography of inulin hydrolysis products using fractionated endo-inulinase (A) and natural inulinase. (B) The hydrolysis conditions were: $40 \mathrm{~g} / \mathrm{L}$ inulin, pH 4.6, enzyme loading $40 \mathrm{U} /\left(\mathrm{g}\right.$ inulin) and $50^{\circ} \mathrm{C}$. Abbreviations: glucose, G; sucrose, GF; 1-kestose, GF2; 1-nystose, GF3; 1-F-1- $\beta$-D-fructofuranosyl nystose, GF4; 1-F-(1- $\beta$-D-fructofuranosyl) -2-nystose, GF5; 1-F-(1- $\beta$-D-fructofuranosyl)-3-nystose, GF6; fructose, F; inulobiose, F2; inulotriose, F3; inulotetraose, F4; inulopentaose, F5; inulohexaose, F6.

Xanthomonas sp., which was purified by a DEAE-Sepharose CL 6B chromatography (Park et al., 1999); A dual endoinulinase system from Xanthomonas sp. and Pseudomonas sp. was developed for IOS production with a enzyme dosage of $460 \mathrm{U} /(\mathrm{g}$ substrate). The IOS yield and DP value of major hydrolytic products after 110 -h hydrolysis were $92 \%$ and equal or greater than 5, respectively (Cho et al., 2001). Some other attempts were carried out to yield IOS from inulin by recombinant endoinulinase. Xu et al. (2016) reported DP values ranged from DP 3 to DP 6 produced by the recombinant endo-inulinase from
A. niger DSM 2466 with a IOS yield of $91.3 \%$. He et al. (2014) reported that the recombinant endo-inulinase from $A$. niger CICIM F0620 was applied for IOS production with a IOS yield of $91 \%$ and hydrolytic products ranged from DP 2 to DP 5 (He et al., 2014).

A higher IOS yield ( $\sim 94 \%)$ and a reasonable distribution of hydrolyzate ranging from DP 2 to DP 7 were observed in this study. These results proved that separation of endo-inulinase and exo-inulinase activities by the inulin-mediated ethanol gradient precipitation could be an effective alternative method to those 
column chromatographic techniques, and achieve a higher IOS yield compared to those by recombinant endo-inulinase.

\section{CONCLUSION}

Inulinases produced by natural $A$. niger contained both endoand exo-inulinase actvities. For IOS production from inulin, it is desirable to use only endo-inulinase as exo-inulinase would produce mainly the monosacchairdes fructose and glucose from inulin. In the present study, we developed a simple fractionation method using ethanol precipitation to separate endo- and exoinulinases present in inulinases. the enriched endo-inulinase produced an IOS product containing DP 2 to DP 7 at a high yield of $\sim 94 \%$.

\section{DATA AVAILABILITY STATEMENT}

The original contributions presented in the study are included in the article/Supplementary Material, further inquiries can be directed to the corresponding author/s.

\section{REFERENCES}

Bao, M., Niu, C., Xu, X., Zheng, F., Liu, C., Wang, J., et al. (2019). Identification, soluble expression, and characterization of a novel endo-inulinase from Lipomyces starkeyi NRRL Y-11557. Int. J. Biol. Macromol. 137, 537-544. doi: 10.1016/j.ijbiomac.2019.06.096

Chi, Z., Chi, Z., Zhang, T., Liu, G., and Yue, L. (2009). Inulinase-expressing microorganisms and applications of inulinases. Appl. Microbiol. Biotechnol. 82, 211-220. doi: 10.1007/s00253-008-1827-1

Chi, Z. M., Zhang, T., Cao, T. S., Liu, X. Y., Cui, W., and Zhao, C. H. (2011). Biotechnological potential of inulin for bioprocesses. Bioresour. Technol. 102, 4295-4303. doi: 10.1016/j.biortech.2010.12.086

Cho, Y. J., Sinha, J., Park, J. P., and Yun, J. W. (2001). Production of inulooligosaccharides from inulin by a dual endoinulinase system. Enzyme Microb. Technol. 29, 428-433. doi: 10.1016/s0141-0229(01) 00414-8

Cho, Y. J., and Yun, J. W. (2002). Purification and characterization of an endoinulinase from Xanthomonas oryzae No.5. Process Biochem. 37, 1325-1331. doi: 10.1016/s0032-9592(02)00018-3

Coussement, P. A. A. (1999). Inulin and oligofructose: safe intakes and legal status. J. Nut. 129, 1412S-1417S.

Ettalibi, M., and Baratti, J. C. (1987). Purification, properties and comparison of invertase, exoinulinases and endoinulinases of Aspergillus ficuum. Appl. Microbiol. Biotechnol. 26, 13-20. doi: 10.1007/bf00282143

Flores, A. C., Morlett, J. A., and Rodríguez, R. (2016). Inulin potential for enzymatic obtaining of prebiotic oligosaccharides. Crit. Rev. Food Sci. Nutr. 56, 1893-1902. doi: 10.1080/10408398.2013.807220

Golunski, S., Astolfi, V., Carniel, N., de Oliveira, D., Luccio, M. D., Mazutti, M. A., et al. (2011). Ethanol precipitation and ultrafiltration of inulinases from Kluyveromyces marxianus. Sep. Purif. Technol. 78, 261-265. doi: 10.1016/j. seppur.2011.02.019

Gu, J., Pei, W., Tang, S., Yan, F., Peng, Z., Huang, C., et al. (2020). Procuring biologically active galactomannans from spent coffee ground (SCG) by autohydrolysis and enzymatic hydrolysis. Int. J. Biol. Macromol. 149, 572-580. doi: 10.1016/j.ijbiomac.2020.01.281

He, M., Wu, D., Wu, J., and Chen, J. (2014). Enhanced expression of endoinulinase from Aspergillus niger by codon optimization in Pichia pastoris and its application in inulooligosaccharide production. J. Ind. Microbiol. Biotechnol. 41, 105-114. doi: 10.1007/s10295-013-1341-z

\section{AUTHOR CONTRIBUTIONS}

WW and QZ: investigation and formal analysis. XL: supervision. XL and WW: writing - original draft. S-TY and XL: writing review and editing. All authors contributed to the article and approved the submitted version.

\section{FUNDING}

This work was supported by the Key Research and Development Program of Jiangsu Province (BF2015007) and the National Natural Science Foundation of China (31000278).

\section{SUPPLEMENTARY MATERIAL}

The Supplementary Material for this article can be found online at: https://www.frontiersin.org/articles/10.3389/fbioe. 2021.679720/full\#supplementary-material

Jiang, X., Zhu, Y., Zhang, W., Guang, C., Zhang, T., and Mu, W. (2019). Efficient production of inulooligosaccharides from inulin by endoinulinase from Aspergillus arachidicola. Carbohydr. Polym. 208, 70-76. doi: 10.1016/j. carbpol.2018.12.053

Jin, Z., Wang, J., Jiang, B., and Xu, X. (2005). Production of inulooligosaccharides by endoinulinases from Aspergillus ficuum. Food Res. Int. 38, 301-308. doi: 10.1016/j.foodres.2004.04.011

Kango, N. (2008). Production of inulinase using tap roots of dandelion (Taraxacum officinale) by Aspergillus niger. J. Food Eng. 85, 473-478. doi: 10.1016/j. jfoodeng.2007.08.006

Mutanda, T., Wilhelmi, B. S., and Whiteley, C. G. (2008). Response surface methodology: synthesis of inulooligosaccharides with an endoinulinase from Aspergillus niger. Enzyme Microb. Technol. 43, 362-368. doi: 10.1016/j. enzmictec.2008.06.005

Naidoo, K., Kumar, A., Sharma, V., Permaul, K., and Singh, S. (2015). Purification and characterization of an endoinulinase from Xanthomonas campestris pv. phaseoli KM 24 mutant. Food Technol. Biotechnol. 53, 146-153.

Park, J. P., Bae, J. T., You, D. J., Kim, B. W., and Yun, J. W. (1999). Production of inulooligosaccharides from inulin by a novel endoinulinase from Xanthomonas sp. Biotechnol. Lett. 21, 1043-1046.

Qiu, Y., Lei, P., Zhang, Y., Sha, Y., Zhan, Y., Xu, Z., et al. (2018). Recent advances in bio-based multi-products of agricultural Jerusalem artichoke resources. Biotechnol. Biofuels 11:151. doi: 10.1186/s13068-018-1152-6

Schuster, E., Dunn-Coleman, N., Frisvad, J. C., and van Dijck, P. (2002). On the safety of Aspergillus niger- a review. Appl. Microbiol. Biotechnol. 59, 426-435.

Shoaib, M., Shehzad, A., Omar, M., Rakha, A., Raza, H., Sharif, H. R., et al. (2016). Inulin: properties, health benefits and food applications. Carbohydr. Polym. 147, 444-454. doi: 10.1016/j.carbpol.2016.04.020

Singh, P., and Gill, P. K. (2006). Production of inulinases: recent advances. Food Technol. Biotechnol. 44, 151-162.

Singh, R. S., Singh, R. P., and Kennedy, J. F. (2016). Recent insights in enzymatic synthesis of fructooligosaccharides from inulin. Int. J. Biol. Macromol. 85, 565-572. doi: 10.1016/j.ijbiomac.2016.01.026

Singh, R. S., Singh, T., and Larroche, C. (2019). Biotechnological applications of inulin-rich feedstocks. Bioresour. Technol. 273, 641-653. doi: 10.1016/j. biortech.2018.11.031

van Oss, C. J. (1989). On the mechanism of the cold ethanol precipitation method of plasma protein fractionation. J. Protein Chem. 8, 661-668. doi: 10.1007/ bf01025606 
Wang, J., Jin, Z., Jiang, B., and Augustine, A. (2003). Production and separation of exo- and endoinulinase from Aspergillus ficuum. Process Biochem. 39, 5-11. doi: 10.1016/s0032-9592(02)00264-9

Xu, J., Yue, R. Q., Liu, J., Ho, H. M., Yi, T., Chen, H. B., et al. (2014). Structural diversity requires individual optimization of ethanol concentration in polysaccharide precipitation. Int. J. Biol. Macromol. 67, 205-209. doi: 10. 1016/j.ijbiomac.2014.03.036

$\mathrm{Xu}$, Y., Zheng, Z., Xu, Q., Yong, Q., and Ouyang, J. (2016). Efficient conversion of inulin to inulooligosaccharides through endoinulinase from Aspergillus niger. J. Agric. Food Chem. 64, 2612-2618. doi: 10.1021/acs.jafc.5b 05908

Zheng, Z., Xu, Q., Liu, P., Zhou, F., and Ouyang, J. (2018). Enhanced inulin saccharification by self-produced inulinase from a newly isolated Penicillium sp. and its application in D-lactic acid production. Appl. Biochem. Biotechnol. 186, 122-131. doi: 10.1007/s12010-018-2730-6

Conflict of Interest: The authors declare that the research was conducted in the absence of any commercial or financial relationships that could be construed as a potential conflict of interest.

Copyright (c) 2021 Li, Zhang, Wang and Yang. This is an open-access article distributed under the terms of the Creative Commons Attribution License (CC BY). The use, distribution or reproduction in other forums is permitted, provided the original author(s) and the copyright owner(s) are credited and that the original publication in this journal is cited, in accordance with accepted academic practice. No use, distribution or reproduction is permitted which does not comply with these terms. 